\title{
Participação e coprodução em política habitacional: estudo de um programa de construção de moradias em SC
}

\author{
Vitor Hugo Klein Jr. \\ Universidade do Estado de Santa Catarina \\ José Francisco Salm \\ Universidade Federal da Bahia \\ Francisco G. Heidemann \\ Universidade Federal de Santa Catarina \\ Maria Ester Menegasso \\ Universidade do Estado de Santa Catarina
}

\begin{abstract}
Respaldado nas teorias de coprodução de bens públicos, este artigo desenvolve e apresenta uma matriz de coprodução do serviço público. A partir desta matriz faz-se uma avaliação da participação do cidadão na implementação de uma política habitacional levada a efeito pela Companhia de Habitação do Estado de Santa Catarina (Cohab/SC), órgão vinculado à Secretaria de Estado do Desenvolvimento Social, Urbano e Meio Ambiente, com a execução do Programa Estadual de Promoção de Assentamentos Humanos e Moradias Populares no período 2003-06. Os resultados obtidos revelam que a participação do cidadão varia desde o contato inicial com o órgão, ou respectivo representante público, durante a execução das obras, até a entrega das casas. Análise pautada na matriz identificou que o tipo e a intensidade da coprodução do bem público ocorreram de formas distintas nos dois municípios observados - Palhoça e Rancho Queimado - , apresentando resultados mais abrangentes e substantivos em favor do último.
\end{abstract}

Palavras-chave: coprodução do bem público; política habitacional; matriz de coprodução; participação dos cidadãos; cidadania.

Participation and coproduction in public policy: a study of a housing program in Santa Catarina Grounded in the co-production theory of public service, this article develops and introduces a matrix of co-production. The matrix is used on the evaluation of citizen participation in implementing a housing policy carried out by Santa Catarina State Housing Company (Cohab/SC), agency linked to the Ministry of Social, Urban and Environment Development, responsible to implement the State

Artigo recebido em ago. 2010 e aceito em jun. 2011.

RAP - Rio de Janeiro 46(1):25-47, jan./fev. 2012 
Program for Promotion of Human Settlements and Popular Housing during the period 2003-06. The results show that citizen participation varies from the time of first contact with the public agency, or with the respective city halls, during the construction, until the delivery of the houses. Analysis based in the matrix identified that the type and intensity of the co-production, occurred in different ways in the both observed cities — Palhoça and Rancho Queimado — featuring wider and substantive results in favor of the latter.

KEY WORDs: co-production theory of public service; housing policy; matrix of co-production; citizen participation; citizenship.

\section{Eu quero apenas}

Eu quero apenas

Sorrir ao acordar

E ao abrir a janela sentir

$\mathrm{O}$ ar da manhã o meu rosto tocar

Eu quero apenas

Ser feliz e sonhar

Ter meu pedaço de chão

E um cantinho pra morar

Eu quero apenas

Amar e viver

Refletir na derrota

E comemorar ao vencer

Eu quero apenas

Plantar e colher

Curtir e admirar a natureza

$\mathrm{E}$ os seus habitantes proteger.

\section{(Niberto Heinz)}

\section{Introdução}

O poema acima foi escrito por um participante de um programa habitacional em uma das reuniões realizadas durante a etapa de construção de sua nova casa. O poeta demonstra e reflete a importância que a moradia tem na vida das pessoas, como a questão habitacional influencia a qualidade de vida dos cidadãos e como estes realizam sua cidadania. Nesta perspectiva, 
envolver os cidadãos na formulação e implementação de uma política habitacional passa a ser um desafio para a administração pública. Maior ainda será esse desafio quando se espera que os beneficiados por esses programas habitacionais participem ativamente na construção das moradias, ou seja, que sejam copartícipes efetivos do programa habitacional a que se associaram. Essa forma de coprodução é uma alternativa para a prestação dos serviços públicos e para o desenvolvimento da cidadania.

A coprodução do bem público, desse modo, é um meio para se articular e implementar uma política habitacional, envolvendo os beneficiários de suas ações, servindo para legitimar o processo democrático e a realização da cidadania. A participação do cidadão acontece em formas e níveis variados, mas deve ser voluntária e consciente. Logo, a coprodução do bem público, com a participação do cidadão, contribui para o desenvolvimento humano, para a educação e para a redução das desigualdades sociais. O conceito de cidadania, nesta ótica, vai além de seu aspecto legal relacionado aos direitos civis, políticos e sociais, exercendo um papel ético substantivo e sociológico, que sai fortalecido pelo sentimento de comunidade e identidade coletiva (Vieira, 1997).

De maneira geral, a prática da participação ajuda a atender a expectativa dos cidadãos, a melhorar a qualidade das políticas públicas, a auxiliar em sua implementação, a responder às necessidades de accountability e transparência e a aumentar a confiança pública no governo. A coprodução do bem público, desse modo, dinamiza a interação entre os agentes públicos e os cidadãos, os quais buscam soluções de forma conjunta para a resolução dos problemas ligados à coletividade. O papel da administração pública, por meio de seus órgãos e agentes, é mediar e promover um espaço público propício à deliberação coletiva, onde os cidadãos possam fortalecer seu senso de justiça e participação. Neste espaço, cidadãos e setor público coproduzem os serviços públicos por meio da cooperação e da responsabilidade compartilhada, em um processo de governança envolvendo diversos atores que atuam direta ou indiretamente na produção do bem público (Denhardt e Denhardt, 2003).

No entanto, a participação e a coprodução do bem público nem sempre foram privilegiadas — na prática — pelos governantes. As políticas públicas promovidas pelo Estado brasileiro até o início da década de 1980 foram marcadas pela exclusão da sociedade civil em sua formulação, implementação e controle, num padrão não democrático de centralização decisória e fragmentação institucional. Por um lado, o resultado disso foi o reconhecimento da complexidade da problemática social do país, em que os desafios de cada área social exigiam respostas singulares; por outro, estabeleceu-se uma autonomia que levava à desarticulação entre as ações das diferentes áreas (Farah, 2001). Entre as áreas afetadas pela falta de articulação está a habitação, que sofreu com a inexistência de serviços complementares de outros setores. Ainda assim, apesar do clima de desconfiança no setor estatal, atualmente é possível identificar no Brasil muitas iniciativas que estabelecem um novo tipo de relacionamento entre sociedade e Estado e que redefinem a esfera pública.

O governo de Santa Catarina tem os alicerces de sua gestão voltados para um modelo descentralizado que, em tese, favorece a coprodução dos serviços públicos. Entre os órgãos da estrutura do governo, a Companhia de Habitação do Estado de Santa Catarina (Cohab/SC), 
órgão vinculado à Secretaria de Estado do Desenvolvimento Social, Urbano e Meio Ambiente foi responsável pela execução do Programa Estadual de Promoção de Assentamentos Humanos e Moradias Populares 2003-06.

Neste artigo, relata-se uma avaliação da participação do cidadão na implementação da política habitacional promovida pelo Programa Estadual de Promoção de Assentamentos Humanos e Moradias Populares 2003-06, com a coordenação da Cohab/SC. Essa avaliação foi realizada contra uma matriz de coprodução do bem público, desenvolvida a partir das tipologias de Whitaker (1980) e Brudney e England (1983). A avaliação que este estudo propõe é relevante, uma vez que a produção acadêmica sobre coprodução do bem público se refere, quase sempre, a serviços de saúde, educação e segurança, deixando de lado questões tão importantes quanto, por exemplo, a política de habitação.

No artigo discute-se, após esta breve (1) introdução, (2) o conceito de participação do cidadão na implementação de uma política pública; (3) elucida-se o entendimento que a literatura dá ao conceito de coprodução e apresenta-se uma matriz de análise; (4) descreve-se a metodologia utilizada para a realização da pesquisa; (5) discutem-se o caso estudado e os resultados da pesquisa em face da matriz de análise; e (6) fazem-se algumas considerações finais.

\section{Participação do cidadão}

Nesta seção, é explorado o conceito de participação do cidadão em algumas de suas variações conforme a literatura sobre o assunto, bem como sua relação com o conceito de cidadania. A participação dos cidadãos - nas decisões políticas, técnicas e administrativas que os afetam diretamente - tem sido tema de debate entre diversas correntes que discutem seu valor e sua viabilidade. Dentro do processo de política pública, a participação do cidadão acontece por meio de processos eleitorais e extraeleitorais (Stewart, 2007). Por extraeleitoral, segundo Dahl (1956), entende-se o processo pelo qual os cidadãos podem participar na construção de políticas entre os períodos de eleição. Os mecanismos utilizados neste tipo de participação foram discutidos por diversos autores, entre os quais Walters, Aydelotte e Miller (2000), Bishop e Davis (2002), Rowe e Frewer (2005) e Ceneviva e Farah (2006). Alguns exemplos desses mecanismos são as assembleias de cidadãos, os júris de cidadãos, os grupos focais, plebiscitos, orçamentos participativos, referendos, surveys, painéis de pesquisa, bate-papos interativos e páginas de internet.

Independentemente do mecanismo participativo utilizado, existe sempre uma distância a ser percorrida entre o administrador público e o cidadão. Para diminuir essa distância, Roberts (2004) propõe a criação de experimentos sociais em que a participação direta dos cidadãos seja possibilitada, apesar dos dilemas e dificuldades existentes. Esses experimentos sociais constituem um espaço público de aprendizagem no qual podem ser utilizados processos deliberativos apoiados em diálogo, colaboração e uso de tecnologia de informação.

O grande desafio, porém, está na operacionalização de uma participação ampla. As instituições desenhadas para deliberar em nome das maiorias muitas vezes estão em descom- 
passo com parte significativa da população. Em sociedades complexas e pluralísticas impõe-se a criação de um espaço para a solidariedade e a representação pública, em que os atores sociais possam aumentar sua capacidade e autonomia para a deliberação de matérias complexas (Melucci e Avritzer, 2000). A capacidade deliberativa dos cidadãos é ressaltada como uma etapa, dentro de um conjunto de cinco dimensões, segundo um tipo ideal de participação (Harbers, 2007).

A primeira dimensão refere-se ao momento da participação do cidadão nas políticas, incluindo monitoramento e implantação. A segunda diz respeito à institucionalização dos processos; esta dimensão é necessária para sustentar a participação no decorrer do tempo. A terceira relaciona-se ao fato de que a participação deve estar voltada para a resolução de problemas concretos. A quarta trata da deliberação face a face, que deve ser componente-chave na experiência democrática, segundo insiste Harbers. A quinta e última dimensão refere-se à legitimidade que advém do processo deliberativo. Estas cinco dimensões especificam as condições em que a participação contribui para a maximização do processo democrático.

Outra importante noção, que está implícita no conceito de participação, é a de cidadania. Na definição de participação dos cidadãos, Roberts (2004) utiliza a visão ampla de cidadão, com uma perspectiva substantiva, que vai além do conceito meramente legal de cidadania, em geral adotado. Pela ótica comunitária, impõe-se reconhecer o papel e a importância do cidadão na participação política (Farrel, 2000); compreende-se que a cidadania tem importância estratégica para a superação dos traços paternalísticos e da falta de accountability na administração pública. Entretanto, para isso são necessárias estruturas cívicas que deem suporte à resolução dos problemas. Essa estrutura cívica, como conceito de nível comunitário, consiste em múltiplas conexões existentes entre o pessoal local e suas organizações voluntárias, na medida em que procuram trabalhar em conjunto para a resolução de seus problemas públicos (Morton et al., 2008). Esse conceito estende a ideia de engajamento do cidadão na esfera pública para um atributo de nível comunitário. Há, dentro dessa noção, evidências de que lugares com estruturas cívicas mais fortes são mais aptos para resolver problemas do que outros com deficiências nesse aspecto (Warren, 2001; Morton et al., 2005). Alguns autores, porém, sugerem que a inabilidade para criar resultados favoráveis pode estar associada à falta de comprometimento dos habitantes da cidade (Orum e Gramlich, 1999). Isso pode estar associado a "um fraco senso de identidade comunitária e/ou à falta de conexões sociais entre os cidadãos locais e os grupos e as organizações" (Morton et al., 2008:48), pois o senso de pertencer ao local onde vivem leva as pessoas a implicações positivas de comprometimento.

Ainda quanto à noção de cidadania, seguindo uma linha conceitual de cidadania plena, Denhardt e Denhardt (2003:97) exploram as condições necessárias ao estabelecimento de um processo de "participação ativa". Estes autores argumentam que algumas experiências positivas de envolvimento do cidadão foram documentadas em inúmeras publicações e que, com base nelas, o Public Management Service Working Groupon Government-Citizen Connections, da Organização para a Cooperação e o Desenvolvimento Econômico (OCDE), definiu três níveis de envolvimento: (1) informação, (2) consulta e (3) participação ativa. No nível da informação, o relacionamento é de uma via, com o governo produzindo e provendo 
informações. No nível da consulta, o governo define as matérias, as questões, e gerencia o processo, enquanto os cidadãos contribuem com opiniões, estabelecendo uma segunda via de relacionamento. Há, porém, autores que argumentam que não basta os cidadãos apenas serem consultados, ou ainda informados, para um processo de participação ativa (Ranson e Stewart, 1989). Importa que eles possam se envolver ativamente no processo de tomada de decisão e assumir responsabilidade por ela e por seus efeitos. Dessa forma, a participação ativa, que corresponde ao terceiro nível da classificação da OCDE, é um relacionamento baseado em parceria. Nesse nível, os cidadãos se engajam ativamente no processo de definição das políticas. Segundo Marschall (2004), esta é uma noção não linear de implementação de política pública, em que a participação do cidadão funciona tanto para estabelecer suas necessidades como para a continuação e preservação das ações.

Deve-se ressaltar que os mecanismos de participação utilizados pelos governos variam muito, assim como a intensidade da participação também varia de sociedade para sociedade (Stewart, 2007). Para estudar esse fenômeno é necessário ter em conta a importância do contexto, cultura e história de cada sociedade. Na América Latina, por exemplo, tem-se o sentimento de uma parcialidade no processo democrático; o sentimento é de que a democracia nesse continente está incompleta (Harbers, 2007). No caso do Brasil, deve-se ter em mente alguns aspectos importantes. No livro Raízes do Brasil, Buarque de Holanda (1995) identifica as origens patriarcais da construção social brasileira. Segundo ele, entender o passado e as tendências personalistas existentes na democracia brasileira, assim como o comportamento do homem cordial, é fundamental para se buscar os moldes participativos verdadeiros no caso brasileiro. Ainda segundo esse autor, não há modelo a ser seguido, mas deve se seguir caminho próprio, respeitando os valores culturais próprios. Para Buarque de Holanda, não existe democracia sem vida democrática, e é pela maximização do potencial político individual que a verdadeira participação viabilizará a democracia.

A partir dessa discussão sobre participação, define-se no próximo tópico o termo coprodução. Destaca-se, também, a participação do cidadão no processo de coprodução do bem público.

\section{A coprodução}

A produção de serviços públicos demanda, cada vez mais, o envolvimento ativo dos cidadãos, compartilhando responsabilidades e trabalhando em cooperação para a implementação das políticas públicas (Denhardt e Denhardt, 2003). Entre os diversos autores que tratam da questão do envolvimento do cidadão, participando de alguma forma da produção da política pública, cabe citar Whitaker (1980), que propõe três situações ou circunstâncias em que pode ocorrer a coprodução: a) quando os cidadãos solicitam assistência aos agentes públicos (verificável pela matriz de análise — quadro 1 - da "requisição de assistência"); b) quando os cidadãos oferecem assistência aos agentes públicos (verificável pela matriz de análise da 
"cooperação com agentes"); e c) quando cidadãos e agentes interagem para ajustar suas expectativas sobre a prestação dos serviços ou das ações (verificável pela matriz de análise da "negociação com agentes").

No primeiro caso — "requisição de assistência" — o cidadão faz a requisição do serviço, demandando a assistência ao órgão público responsável. O movimento parte do cidadão para o setor público. Neste caso, cidadãos e agentes públicos encontram-se sob tensão entre a identificação daquilo que o cidadão solicita e os julgamentos e interpretações do agente sobre esta solicitação. Neste ponto Whitaker deixa claro que os agentes públicos devem se guiar pela lei e considerações de equidade bem como pelas solicitações do indivíduo. Isso ocorre porque os servidores públicos têm fé pública e devem exercer a accountability de seus atos no uso dessa responsabilidade. Significa que deve haver um equilíbrio entre a solicitação do cidadão e a discricionariedade do servidor, o qual, durante o processo, deve deixar claro o embasamento de seus atos.

No segundo caso — “cooperação com agentes" —, os cidadãos dão assistência aos agentes públicos. O movimento parte do sentido contrário ao do primeiro caso. O órgão público vai ao encontro do cidadão, que empresta seu apoio e cooperação ao setor público, auxiliando-o no atendimento a uma demanda. Esse apoio ou cooperação deve ser consciente e voluntário, pois é um importante meio para influenciar políticas públicas.

O terceiro caso trata da interação entre agentes e cidadãos — "negociação com agentes" - por meio de ajustamentos mútuos. Nas trocas realizadas por meio dessa interação, cidadãos e agentes dividem a responsabilidade pela decisão de suas ações, fato que gera maior legitimidade a seus atos, atendendo à accountability que é exigida nos processos contemporâneos de governança. A participação dos cidadãos por meio desse ajustamento mútuo de expectativas é uma maneira de tornar os serviços mais efetivos (Denhardt e Denhardt, 2003).

Na perspectiva econômica, Brudney e England (1983) propõem o conceito de coprodução como um mix de atividades que os agentes de serviço e os cidadãos realizam em conjunto para prover os serviços públicos, uma iniciativa que concorre para a melhoria da eficiência dos custos e da qualidade dos serviços em tempos de dificuldades fiscais para o Estado. A partir desse conceito, os autores distinguem três tipos de coprodução: (1) a coprodução individual, (2) a coprodução em grupo e (3) a coprodução coletiva. A tipologia de coprodução sugerida por Brudney e England forma uma hierarquia de atividades de coprodução, em que cada grau é determinado pela natureza dos benefícios (individual, grupal ou coletivo) e o grau de sobreposição entre as atividades dos produtores regulares (regular producers-governo) e dos consumidores (consumers-cidadãos).

No nível inferior da hierarquia de Brudney e England está a coprodução individual, que é definida como aquele tipo de participação em que o principal beneficiário da ação pública é o próprio indivíduo. Nesse caso, segundo os autores, os benefícios agregados para a pólis são mínimos, sendo difícil distinguir essas atividades da obrigação cívica regular. No segundo nível, está a coprodução em grupo, que envolve a participação voluntária de um conjunto de 
cidadãos, em um esforço de melhorar a qualidade e a quantidade dos serviços que consomem. Um exemplo de coprodução em grupo são os grupos de vizinhos que vigiam a redondeza de suas casas, com o propósito de garantir a segurança pública, prática conhecida nos EUA com o nome de neighborhoodwatchers. No último estágio da hierarquia está a coprodução coletiva, em que os benefícios do processo são usufruídos por toda a comunidade, por meio de um ambiente de cooperação entre produtores regulares e consumidores. Neste estágio, segundo Brudney e England, a coprodução a ser alcançada seria "substancial". As ações de coprodução, na perspectiva econômica, aumentam de acordo com os beneficiários desta. Partem de uma individualidade, passando por grupos específicos de cidadãos que apoiam e dão suporte às iniciativas promovidas pelo setor público ou iniciadas em prol de seu interesse particular, atingindo um grau ótimo de benefícios para a comunidade quando exercida dentro de uma coletividade.

Outro modelo de coprodução ocorre quando os cidadãos e administradores públicos compartilham responsabilidade e trabalham juntos na implementação de políticas e programas públicos (Sundeen, 1985; Denhardt e Denhardt, 2003). Segundo esse modelo, os conceitos de confiança, cooperação e compartilhamento de responsabilidades, juntamente com os ideais de comunidade e cidadania, são vistos como pressupostos da participação e do engajamento do cidadão no processo de construção de uma comunidade mais forte e participativa. Há, nesta visão, uma orientação para os atributos da construção de um espaço público pelas organizações, em que os cidadãos e administradores possam trabalhar em conjunto para a construção de políticas públicas. Nesse espaço o cidadão participa nas decisões do governo e na provisão dos serviços. Espaço onde cidadãos se articulam e promovem um processo de deliberação coletiva, por meio de noções de igualdade e liberdade, o que serve para guiar uma ação comum em nome do bem público (Arendt, 1997). Essa orientação de coprodução vai além dos benefícios da redução de custos provocada por crises fiscais, reorientando o foco exclusivo em eficiência e interesse próprio para um foco que recupera os valores de cidadania e bem comum (Cooper e Kathi, 2005).

Muito embora o processo de coprodução possa ocorrer tanto em nível individual quanto grupal ou coletivo (Brudney e England, 1983), os benefícios substanciais e duradouros devem ser buscados pela participação coletiva, alinhando-se à busca de uma "participação autêntica" (Denhardt e Denhardt, 2003) ou de uma "participação direta do cidadão" (Roberts, 2004). Os ajustamentos mútuos entre a administração pública e o cidadão (Whitaker, 1980) também produzem resultados substanciais e melhoram a efetividade dos serviços públicos. A implementação de políticas públicas, nesta perspectiva, pode ser vista como um processo não linear, permitindo aos cidadãos que participem, comunicando suas necessidades e desejos, influenciando o processo de formulação e contribuindo para a implementação e preservação dos programas públicos (Marschall, 2004).

A partir dessas considerações e com base na discussão do pensamento dos autores referidos, é possível identificar, na figura 1, os pressupostos e os benefícios da coprodução. 
Figura 1

\section{Pressupostos e benefícios da coprodução}

\begin{tabular}{|c|c|}
\hline Pressupostos & Benefícios \\
\hline $\begin{array}{l}\text { v Voluntariado } \\
\text { v Consciência } \\
\text { v Envolvimento positivo } \\
\text { v Comportamento ativo } \\
\text { v Participação coletiva } \\
\text { - Confiança mútua } \\
\text { v Compartilhamento de } \\
\text { responsabilidade e poder } \\
\text { - Processo democrático }\end{array}$ & $\begin{array}{l}\text { Vesenvolvimento humano } \\
\text { v Educação } \\
\text { v Terapia e integração } \\
\text { v Proteção à liberdade } \\
\text { v Redução de desigualdades } \\
\text { v Cidadania plena } \\
\text { v Accountability multifacetada } \\
\text { v Melhora da confiança } \\
\text { no governo }\end{array}$ \\
\hline
\end{tabular}

Fonte: elaborado pelos autores com base na referência teórica.

Partindo das concepções e propostas teóricas sobre participação e coprodução até aqui desenvolvidas, propõe-se uma matriz de análise (quadro 1) que estabelece a relação entre os diversos tipos de envolvimento (tipologias) e as situações (grau de intensidade) em que pode ocorrer a coprodução.

$$
\text { Quadro } 1
$$

\section{Matriz de coprodução}

\begin{tabular}{|cccc|}
\hline Coprodução do bem público & \multicolumn{3}{c|}{ Formas possíveis de envolvimento } \\
\hline Tipologias & $\begin{array}{c}\text { Requisição de } \\
\text { assistência }\end{array}$ & $\begin{array}{c}\text { Cooperação (não) } \\
\text { com agentes }\end{array}$ & $\begin{array}{c}\text { Negociação com } \\
\text { agentes }\end{array}$ \\
& $(1)$ & $(2)$ & (3) \\
Individual (I) & I1 & 12 & I3 \\
Grupal (G) & G1 & G2 & C3 \\
Coletiva (C) & C1 & C2 & C3
\end{tabular}

Fontes: elaboração dos autores com base em Withaker (1980) e Brudney e England (1983).

Esta matriz foi montada a partir das formulações teóricas sobre coprodução desenvolvidas por Whitaker (1980) e Brudney e England (1983). Os níveis dispostos na coluna lateral esquerda do quadro fazem parte da tipologia apresentada por Brudney e England (1983). As formas possíveis de envolvimento entre o cidadão e os agentes, dispostas no sentido horizontal da matriz, correspondem às propostas sobre coprodução do bem público elaboradas 
por Whitaker (1980). Dessa forma, a matriz contempla as três possibilidades de interação do cidadão com os agentes públicos em suas diferentes intensidades $(1,2,3)$ e os tipos possíveis de coprodução ( $\mathrm{I}, \mathrm{G}, \mathrm{C}$ ). Isso permite fazer uma análise dinâmica da coprodução, uma vez que oferece diferentes possibilidades de interação entre o cidadão e os agentes públicos, podendo ainda identificar essas posições em momentos distintos da agenda política.

Assim, o cidadão, no caso do nível individual, pode requerer assistência do agente público (I1), pode cooperar, ou não, com os agentes públicos (I2), ou pode, ainda, negociar com os agentes públicos (I3). Essas formas possíveis de interação entre cidadãos e agentes públicos, visando à coprodução do bem público, pode se estender até a coletividade de cidadãos que negocia com agentes públicos (C3).

A concepção da matriz leva em conta a necessidade de se estabelecer uma relação entre as possibilidades de interação dos cidadãos e dos agentes públicos. Essa relação vai permitir avaliar, conforme se tenta expor no artigo, o grau de participação do cidadão na implementação do Programa Estadual de Promoção de Assentamentos Humanos e Moradias Populares de 2003-06, coordenado pelo órgão responsável pela política habitacional de Santa Catarina (Cohab/SC). Na próxima seção será apresentada a metodologia utilizada no estudo.

\section{Metodologia da pesquisa}

Como será detalhado no tópico correspondente à apresentação dos dados, a realidade estudada é o Programa Estadual de Promoção de Assentamentos Humanos e Moradias Populares, no período 2003-06, coordenado pela Companhia de Habitação do Estado de Santa Catarina. A observação limitou-se à implementação do programa em dois municípios: Palhoça, para beneficiários de imóveis urbanos; e Rancho Queimado, para beneficiários de imóveis rurais. O estudo se caracteriza como método de caso e utiliza uma abordagem qualitativa. Optou-se por esta abordagem porque ela facilita o entendimento do significado que os beneficiários atribuem ao programa. Em outras palavras, ela permite entender como os beneficiários avaliam sua participação e sua interação com os agentes públicos no processo de coprodução, tanto antes, quanto durante e mesmo depois de sua implementação. Para efeitos desse estudo, deve-se considerar, também, que a pesquisa quantitativa examina um fenômeno decompondo suas partes, enquanto a pesquisa qualitativa trabalha com o funcionamento do todo, trazendo um resultado descritivo, em que o pesquisador é o principal responsável pela coleta de dados e análise. Desse modo, a estratégia de estudo de caso utilizada nesta pesquisa permite uma avaliação descritiva mais ilustrada do Programa Estadual de Promoção de Assentamentos Humanos e Moradias Populares (Yin, 2005). A coleta dos dados se fez por meio de pesquisa documental e de entrevistas com os participantes do programa.

Na pesquisa documental, o foco foi a cartilha do Programa Nova Casa, em especial a apresentação e diretrizes. Assim, puderam ser pesquisadas as partes mais relevantes para o tema em estudo e sua relação com as teorias de participação e coprodução, observando em que momento e com que intensidade a prática encontra a teoria. Durante o período 2003-06, 
165 cidadãos foram beneficiados com imóveis, sendo 110 de Palhoça e 15 de Rancho Queimado. Para este estudo foram escolhidos aleatoriamente, em uma primeira etapa, cinco beneficiários de imóveis, sendo dois de Palhoça e três de Rancho Queimado, e, em um segundo momento, mais 16 beneficiários — oito de Palhoça e oito de Rancho Queimado. Além disso, tomou-se a decisão de entrevistar um dos responsáveis pelo Programa na Prefeitura de Rancho Queimado, já que era necessário entender, com maior profundidade, como o programa foi implementado nesse município. As entrevistas complementaram os dados da pesquisa documental realizada a partir da cartilha, envolvendo as diretrizes básicas e a apresentação do programa.

No próximo tópico serão apresentados os detalhes do caso em estudo, bem como os dados colhidos da cartilha do Programa Estadual de Promoção de Assentamentos Humanos e Moradias Populares, relativo ao período 2003-06. Também serão apresentados os resultados das entrevistas e a discussão e análise dos dados, utilizando-se a matriz de coprodução desenvolvida neste trabalho.

\section{Caso estudado e os resultados da pesquisa em face da matriz de análise}

Neste tópico se apresenta, em primeiro lugar, o caso em estudo e os dados levantados a partir da cartilha; em seguida, são apresentados os resultados das entrevistas com os beneficiários do programa e a respectiva discussão e análise dos dados.

\subsection{Programa Nova Casa}

A Companhia de Habitação de Santa Catarina (Cohab/SC), órgão vinculado à Secretaria do Desenvolvimento Social, Urbano e Meio Ambiente do Estado, é responsável pela coordenação das ações relativas à solução da habitação popular em Santa Catarina. O Programa Nova Casa, executado pela Cohab/SC, tem o objetivo de promover o atendimento, na área habitacional, a famílias de mais baixa renda, desenvolvendo ações integradas e articuladas com outras políticas setoriais, visando à melhoria substantiva da qualidade de vida da população catarinense.

Como articulador da política habitacional do estado, a Cohab/SC estabelece parcerias interinstitucionais para a formulação de seus programas, alinhando-os às recomendações do capítulo 27 da Agenda 21. Essas recomendações tratam do fortalecimento do papel das Organizações Não Governamentais (ONGs), das entidades (categorias) profissionais e da sociedade civil em geral (movimentos e organizações populares). A formulação do programa em tela foi feita, em uma etapa inicial de delineamento interno, pela Cohab/SC; e, posteriormente, tramitou pelas entidades envolvidas, entre as quais: a Secretaria de Estado do Desenvolvimento Social, Urbano e Meio Ambiente; a Caixa Econômica Federal; o Incra; o Crea; a Secretaria de Estado da Agricultura e Política Rural; a Epagri; a Cidasc; o Ipesc; os sindicatos dos servidores públicos; o Movimento dos Pequenos Agricultores; e a Ufeco. A essas entidades 
coube formular sugestões e contribuições em diversas reuniões, de forma a tornar o programa articulado e exequível.

Conforme preconiza a cartilha, por ocasião da implantação de um programa devese atentar para a proposta de criação de fóruns e seminários, com vistas à viabilização de uma ação participativa. A participação é reforçada na introdução da cartilha do programa e nas premissas explicitadas nas diretrizes básicas do programa, que fazem, novamente, referência ao envolvimento de instituições de diversos segmentos. O programa também considera importante a formação de parcerias entre instituições que envolvem segmentos sociais e entidades financiadoras. Entre os parceiros que devem ser articulados e integrados aos objetivos voltados à melhoria habitacional das famílias mais pobres estão os fundos habitacionais, os órgãos representativos das categorias profissionais vinculadas (Crea, associações, institutos, sindicatos, cooperativas) e a sociedade civil em geral (movimentos e organizações populares).

São apresentados, a seguir, os dados das entrevistas com os beneficiários do programa estudado, nos municípios de Palhoça e Rancho Queimado, bem como do representante desta última, responsável pela articulação do programa naquela cidade.

\subsection{Entrevistas com os beneficiários}

As entrevistas foram realizadas com beneficiários residentes nos municípios de Palhoça (situação 1, 10 moradias urbanas) e Rancho Queimado (situação 2, 10 moradias rurais). Também foi realizada uma entrevista com o responsável pelo programa na prefeitura de Rancho Queimado.

Quando foi perguntado como conheceram o programa, os beneficiários relataram que procuraram informações na comunidade, tendo sido encaminhados para a pessoa que representa o órgão responsável pelo programa, o qual fez o atendimento e os encaminhamentos necessários. Seguem alguns relatos, utilizando as expressões dos entrevistados:

Não foi por meio de anúncio na televisão nem no jornal, porque a gente também não lê jornal assim direto. Se tem anúncio no jornal eu não sabia, nem a mulher. E na televisão também não foi. A gente... acho que tipo correu um pouco atrás e teve uma luz, teve um, teve um cara que ele, ele tava procurando assim, tava procurando as pessoas mais necessitadas, que precisavam disso; foi o funcionário [da Cohab]. Ele viu que nós tava precisando muito e disse: "Oh! vou dá uma força pra vocês, que a Cohab tem um plano que pode ajudar as pessoas que tão necessitadas". Eu disse: "Pô, cara, credo. Isso aí é uma loteria pra nós". Foi por aí. (entrevistado 1, moradia urbana, Palhoça)

Eu comecei a indagar aí pela rua, né. Quem que não sabia quem é que ia me ajudar a fazer uma casinha. Fui indagando. Aí um dia tava na nega, perguntei, e a nega perguntou pra ele. Aí mandou eu lá, eu fui. (entrevistado 2, moradia urbana, Palhoça) 
Entrevistador: Eu queria que você me contasse essa história, como é que você ficou sabendo do programa, e como é que você começou a participar?

Beneficiário: Fiquei...por meio do Nenê... [nome fictício] da prefeitura lá...e do Pedro [nome fictício]. (entrevistado 4, moradia rural, Rancho Queimado)

Entrevistador: Como o senhor ficou sabendo do Programa Nova Casa?

Beneficiário: Olha, aquilo já faz uns par de anos, né. Aquilo veio o programa e o meu filho é que foi dá o nome, e que eu tava esquecido, né. Aquilo tava esquecido. E daqui a pouco veio, acho que foi você [representante da prefeitura] e o Joel e o Joseney, né. E eu morava lá naquela casinha velha de material lá. Daí me perguntaram se eu queria e eu disse: "Eu quero sim, se tiver vaga...”. Quem é pobre já viu, né...pega o que ganhar, né. Aí eu peguei, e veio também. (entrevistado 12, moradia rural, Rancho Queimado)

É importante notar que a informação a respeito do programa surge entre a comunidade e os representantes da prefeitura, pois, segundo os relatos, poucos utilizam a mídia como um recurso de informação, principalmente no que diz respeito à moradia.

Entrevistador: Como a senhora ficou sabendo do Programa Nova Casa?

Beneficiário: Daí foi pelo, como é que eu vou dizer, pelo dono da loja lá, o Pedro, da Sofia. [nomes fictícios] (entrevistado 14, moradia urbana, Palhoça)

Entrevistador: É da comunidade, ele?

Representante da prefeitura: Ele tem uma loja de construção aqui na Palhoça.

Entrevistador: Como é que você ficou sabendo do Programa Nova Casa?

Beneficiário: É porque eu tenho uma vizinha minha, que trabalha no posto de saúde, trabalhava, a Julia, que era coordenadora do posto de saúde ali da ponte [...] daí eu falei, expliquei minha situação pra minha vizinha, se por acaso ela não...que eu encontrei ela na rua, até eu tava indo lá pra Palhoça, daí eu disse: "Você sabe alguém que eu poderia comprar umas madeiras um pouquinho mais barata?". Que eu tô precisando, que minha casa tava quase caindo. Daí ela veio aqui e tudo, daí ela disse assim: "Ó, fala com a Carol da habitação". Que a Rita foi uma do cabelo vermelho, eu falei uma vez com ela. [...] Daí ela que disse que era pra mim me inscrever, né, daí ela que explicou sobre isso aí, sobre o projeto da Cohab, da habitação, daí ela explicou como funcionava tudo...[nomes fictícios] (entrevistado 19, moradia urbana, Palhoça)

Entrevistador: Como é que vocês ficaram sabendo do Programa Nova Casa?

Beneficiário: Porque aí um vereador tinha falado pra minha filha, aí nós fomos lá na prefeitura e daí foi falado, né. (entrevistado 20, moradia urbana, Palhoça)

Entrevistador: Como é que você ficou sabendo do programa Nova Casa?

Beneficiário: Eu encontrei com uma vizinha minha, que ela é minha amiga, e ela me indicou 
esse programa da prefeitura, e eu achei interessante e resolvi participar, né...(entrevistado 21, moradia urbana, Palhoça)

Observa-se, pelas entrevistas, que os beneficiários reportam-se sempre ao caráter de "ajuda" que é oferecida pelo órgão.

A comunidade aplaude, esse, um ato desse, né, que não é sempre que acontece. Aí quando eles viram, pô, realmente funcionou, ajudaram uma família que precisava. É isso que todo mundo percebeu, os caras vieram aqui, ô aquele pessoal teve sorte. Teve uma ajuda da Cohab. (entrevistado 1, moradia urbana, Palhoça)

Fiquei muito contente, que eu não tinha onde morar, tava morando na rua, né, tava morando na rua, não tinha nada. Me ajudaram. Pra mim, todo mundo foi bom. Fui muito bem tratada. Tô muito contente dessa casinha, tô muito contente, muito contente mesmo, tô no céu. (entrevistado 2, moradia urbana, Palhoça)

Entrevistador: Então a participação da prefeitura...

Beneficiário: Foi muito importante. Isso aí é uma coisa que eu canso de dizer pra eles, eles sabem disso, tanto o Nazareno quanto o Joseney, que é uma coisa que eu devo pra eles, uma gratidão que eu tenho assim, que eu sempre vou ter. Foi uma ajuda, que se não fosse o esforço deles, nós não teríamos conseguido, né. Estaríamos até agora do lado da estrada, morando na poeira. (entrevistado 13, moradia rural, Rancho Queimado)

Deve-se ter em conta a importância da moradia na vida dos beneficiários em questão. Como foi observado ao longo das visitas e entrevistas, muitos beneficiários tinham dificuldade no entendimento dos procedimentos legais para fazer parte do programa. Outros, em virtude de terem o dia tomado pelo trabalho, tinham até mesmo dificuldade de comparecer à prefeitura. Daí a importância de a administração pública ir ao encontro, principalmente em se tratando de uma comunidade carente de recursos, e prestar esclarecimentos aos cidadãos. Reforça-se a importância dessa "ajuda", segundo o entendimento dos beneficiários, pois se verifica, em alguns depoimentos, a visão dos beneficiários e cidadãos sobre o funcionamento dos programas públicos e toda a ansiedade envolvida na questão.

Entrevistador: Mas a senhora ficou sabendo através da comunidade?

Beneficiário: Olha, isso eu não lembro bem direito como é que foi. Eu acho que até que foi através da prefeitura que um dia a gente escutou que tava sendo feita a inscrição. Eu não lembro bem, eu acho que tava na praça e alguém me falou, daí eu comentei com eles, vamos fazer a inscrição de novo. Vamos arriscar de novo. Daí eles disseram: "Ah, vocês podem esquecer, nunca que vai sair essas casas; esse é de novo um projeto que vem e vai morrer lá na gaveta do prefeito, do chefe de gabinete, e vocês não vão nem chegar a ver a cor da casa. Ainda mais pro caso de vocês". Que 
aqui era um lugar meio esquecido, né. Então a gente fez a inscrição e pra nossa surpresa foi uma das primeiras que saiu. (entrevistado 13, moradia rural, Rancho Queimado)

Entrevistador: A comunidade percebe esta satisfação, opina sobre isso?

Beneficiário: Acho que sim, porque eles...eles assim, você é muito puxa-saco do Nazareno e do Joseney, mas não é. É que assim eu vejo que eles realizaram o sonho de tantas pessoas, que outros que estavam antes, no anterior, poderiam ter realizado, e nunca se preocuparam em ajudar os outros. É que é assim, há uns tempos atrás colocaram assim: "Quem não tem uma casa pra morar, é porque é malandro, porque não quer". Mas na verdade, você vivendo, você vê que não é bem assim, não é todos que conseguem...então...(entrevistado 13, moradia rural, Rancho Queimado)

Deve-se atentar, no entanto, que a visão dos beneficiários sobre a "ajuda" pode assumir conotações paternalistas e de apadrinhamento, no contexto cultural que é marcante na história brasileira, conforme demonstra a revisão teórica levantada. Um exemplo é o depoimento que se segue.

Entrevistador: A partir do momento que a senhora ficou sabendo do programa, como a senhora fez para participar do programa?

Beneficiário: Olha, no começo eu fiquei meio assim, ele falou: "Vai, vai lá". Mas como...tinha um vereador aqui perto... Daí eu pedi uma ajuda pra ele, ele também deu um empurrãozinho também, né [...] Então ele, também ele...deu uma mão por lá... encaminhou por lá, e eu cheguei lá e fui bem atendida por eles.

Entrevistador: A senhora teria mais alguma coisa pra dizer?

Beneficiário: Queria agradecer eles que me ajudaram, né. Pra mim, nossa, né...o prefeito, depois foi preciso ajeitar lá[...] Foi bem fácil pra mim, eu tava precisando mesmo, eu tava precisando mesmo...(entrevistado 14, moradia urbana, Palhoça)

Importa ressaltar, neste ponto, que foram notadas diferenças nos modelos de participação para a construção das moradias urbanas e rurais (situação 1 e situação 2), ou seja, entre os municípios de Palhoça e de Rancho Queimado. No exemplo das moradias rurais de Rancho Queimado, a prefeitura, depois de selecionadas as famílias a serem beneficiadas pelo programa, realizou diversas atividades relacionadas à nova moradia com os beneficiários. Essas atividades tinham como objetivo criar uma dinâmica participativa e articular a execução da obra com os beneficiários. Muito embora essas reuniões façam parte da programação social demandada na execução do programa, os resultados obtidos parecem variar entre os dois municípios. A participação dos beneficiários nas reuniões promovidas para planejar a execução da obra, segundo o representante da prefeitura de Rancho Queimado:

Foi excelente, assim, superou a expectativa. Por exemplo, a gente fez a dinâmica do barbante, aquela questão assim de jogar o barbante um pro outro, mostrar que a gente tava formando um grupo ali, que esse grupo fosse coeso né, e assim, mostrando que um tava dependendo do outro. 
Por exemplo, se tivesse fazendo a casa de um vizinho e não desse certo, que ele desse as ideias, como é que ele fez, como é que ele conseguiu resolver o problema, entendeu. (entrevistado 3 , representante da prefeitura de Rancho Queimado)

Seguem-se depoimentos dos beneficiários de Rancho Queimado em relação às reuniões.

Entrevistador: Qual o tipo de informação que vocês discutiam no grupo?

Beneficiário: Assim, como a gente ia deixar a casa da gente, né. Os cuidados, tanto interior quanto exterior da casa, do jardim, como a gente ia cuidar do lixo que a gente ia produzir e tal, né, pra não ter só uma casa e também não ter o restante dos cuidados necessários. (entrevistado 8, Rancho Queimado)

Entrevistador: Esses grupos que participavam, a senhora sabe com que frequência se reuniam? Beneficiário: De 15 em 15 dias, talvez já tinha até de oito em oito dias...conforme lá o pessoal que podia vir também, né. (entrevistado 9, Rancho Queimado)

Entrevistador: Nessas reuniões existia alguém que representava vocês na comunidade, no grupo? Beneficiário: Não, a gente se reunia até pra falar sobre o que a gente achava sobre jardinagem, sobre esgoto, sobre como arrumar a casa, né, pintura...

Entrevistador: Essas informações iam além da construção?

Beneficiário: Eu acho que seria....a gente tinha que ter, né...até não só pra mim, mas pros outros também, né... Estavam vendo que a gente tinha que trocar fichas...

Entrevistador: As pessoas compartilhavam essas informações?

Beneficiário: Aham, a gente falava bastante sobre isso...(entrevistado 10, Rancho Queimado)

Entrevistador: Vocês discutiam o que lá na reunião?

Beneficiário: Não, eles só perguntavam o que que tinha que fazer, né, e era assim tal, sabe como é que é, né...esclarecer, né, ver como é que era as coisas, né. Era o pagamento, tal e coisa, de tudo tinha, né. Ah, funcionou tudo certo, pra mim funcionou certo. (entrevistado 12, Rancho Queimado)

Entrevistador: O que a senhora acha que foi bastante importante nas reuniões?

Beneficiário: Assim, que cada um também pôde dar opinião e colocar o que que tava significando a casa pra cada um, né, porque a gente viu que todos que ganharam a casa eram realmente pessoas que precisavam, né, e foi colocado assim bem à vontade o lugar e como que a gente ia fazer.

Entrevistador: Existia, nessas reuniões, ou durante outras horas, outros momentos, alguma pessoa que representava esses beneficiários na comunidade?

Beneficiário: Não, todos falavam. Todos tinham voz de vez pra falar. (entrevistado 13, Rancho Queimado) 
Abaixo, alguns depoimentos sobre as reuniões dos beneficiários de Palhoça.

Entrevistador: O que era repassado nessas reuniões, a senhora poderia me dizer?

Beneficiário: Era no salão, né, no Palhoção, como é que funcionava tudo, a última reunião eu tive como esgoto, né, as fossas, higiene, então foi uma coisa muito boa assim...tivemos várias reuniões, né, e bom uso da casa, no final, né. (entrevistado 17, Palhoça)

Entrevistador: Foram quantas reuniões, você sabe me dizer?

Beneficiário: Acho que umas quatro reuniões.

Entrevistador: E ele trouxe outro tipo de informação nessa reunião, além da casa?

Beneficiário: Não, só da casa, né. (entrevistado 17, Palhoça)

Entrevistador: Foi feita alguma reunião para discutir o programa?

Beneficiário: Foi feita, aham.

Entrevistador: O que ele comentou nessa reunião?

Beneficiário: Aí ele já trouxe as informação, já pediu os documento da gente pra fazer a inscrição, né, pra fazer a nova casa, daí a gente ficou esperando, de vez em quando a gente ia...sempre vinha, todos os meses tinha reunião pra gente, sempre eles vinham pra se... (entrevistado 18, Palhoça)

Outra questão relevante, no caso de Rancho Queimado, foi a realização das atividades em que o beneficiário desenhava seu jardim. Essas atividades serviam para fornecer uma perspectiva ao beneficiário de uma moradia e, ao mesmo tempo, possuíam cunho educativo.

A ideia foi o seguinte... fizemos o desenho da casa... a gente pediu que ele desenhasse... qual é a perspectiva... como é que eles poderiam estar vendo essa propriedade deles... esse jardim... esse entorno da casa, sabe... Porque a gente sempre trabalhou na seguinte perspectiva desde a primeira reunião: vamos tirar a galinha de volta da casa. É importante ele ter a galinha? Claro que é. O agricultor, o colonozinho não tem galinha, porco... tá... não dá nem pra dizer que ele é... tudo isso é pra ele... e não depender do mercado... e ainda tem um produto mais saudável. É tudo, é efetivamente aquela qualidade de vida que se preza, ele tem que ter. Mas esse bicho não pode estar do lado da casa. (entrevistado 3, representante da prefeitura de Rancho Queimado)

Indagados sobre o relacionamento com a prefeitura, os cidadãos, beneficiários do programa, responderam como segue.

Entrevistador: Como a senhora considera que funcionou o relacionamento com a prefeitura? Beneficiário: Muito bom, muito bom. Eles tão de parabéns mesmo, chorei na hora que eles chegaram de agradecer, fiquei feliz porque isso era uma coisa que eu esperava a tantos anos. Merece os parabéns mesmo. (entrevistado 9, Rancho Queimado) 
Entrevistador: Como o senhor considera que foi o relacionamento com a prefeitura? Beneficiário: O relacionamento com a prefeitura foi bom. Foi excelente. (entrevistado 11, Rancho Queimado)

Entrevistador: Como a senhora considera que foi o relacionamento com a prefeitura? Beneficiário: Foi tranquilo, sempre na época a gente chamou, ele [Nazareno] e o Joseney, que na época eles que tavam responsável, e a gente chamava: "Ó, tá tendo um probleminha ali, o carpinteiro não tá fazendo do jeito que a gente quer, tá meio torto, ele botou uma madeira que a gente não...", logo ele vinha. (entrevistado 13, Rancho Queimado)

Entrevistador: E o relacionamento com a prefeitura?

Beneficiário: Não, eles foram bem humanos, foram bastante humanos. A Elba assim ajudou bastante atrás da papelada, essa tal de Carol, ela também ajudou bastante. Não, eles foram muito humanos, eu não tenho nada o que falar. Sempre assim, se acontecia algum problema, algum papel, algum assinaturazinha, que eu esqueci de assinar uma folha ela ligava pra mim: "Ó...tem isso aqui, aquele, aquele outro". Não, eles foram bem humanos, se eu falar mal eu tô sendo injusta. [nomes fictícios] (entrevistado 19, Palhoça)

É compreensível que haja gratidão, tanto pelo fato do atendimento a uma necessidade básica, que é importante para os beneficiários, quanto pelo fato do auxílio nos procedimentos legais para a inclusão no programa. O tópico seguinte apresenta a discussão e a análise dos dados e das informações que foram obtidos na cartilha e nas entrevistas.

\subsection{Análise dos dados}

As recomendações descritas no texto do Programa Nova Casa salientam a preocupação de se adotar um modelo participativo, envolvendo categorias de diversos segmentos sociais, governos locais e demais órgãos detentores de recursos em um trabalho articulado. Este trabalho de articulação demonstra como os governos estão mudando a maneira de desenvolver suas políticas públicas, com os mecanismos tradicionais de governos hierárquicos cedendo espaço para uma crescente descentralização de interesses, em um processo de governança em que fazem mais sentido a interação e o envolvimento do que o controle. Isso demonstra que há uma preocupação com a complexidade da viabilização do programa e que ele seja legitimado pelos cidadãos e demais entidades.

Pode-se observar, pela pesquisa documental, que, na primeira etapa, durante a formulação do programa, a participação é restrita a uma consulta, fato que corresponde à descrição e denominação utilizada pela OECD. A Cohab/SC define as matérias e questões pertinentes ao programa e as apresenta, posteriormente, às partes envolvidas. Na matriz de análise há uma evolução do nível grupal (G), na primeira etapa, para o nível coletivo (C), na segunda. 
Embora o envolvimento de diversos atores esteja explícito no documento, ao se fazer a análise textual, constata-se que não fica clara qual foi a forma ou grau de envolvimento - intensidade, segundo o modelo de análise proposto - de cada um dos beneficiários na formulação das diretrizes e ações do programa. As entrevistas demonstram que não houve participação dos beneficiários via associações, sindicatos ou demais organizações que permitisse a eles exercer influência na concepção do plano (formulação política). Isso encerra a análise no nível de participação do cidadão via órgãos representativos.

Quanto ao tipo de participação do cidadão, pode-se observar, pelas entrevistas realizadas nas duas situações estudadas, que esta aconteceu no nível de execução do programa, desde o momento em que o beneficiário descobre a existência do programa e durante a construção de sua casa em parceria técnica com a Cohab/SC. Para entender melhor, é necessário explicar aqui que o programa proporciona o financiamento da casa dos subsidiários, com parte sendo subsidiada pelo governo federal. Os beneficiários recebem R\$ 9 mil, dos quais R 6 mil são subsidiados com verba pública e R \$ 3 mil financiados em longo prazo. As parcelas desse valor vão sendo liberadas pelas respectivas prefeituras ao longo da construção da casa, que fica sob a responsabilidade do beneficiário, mas com supervisão técnica de cada prefeitura, que auxilia os beneficiários na execução da obra. Assim, o relacionamento de consulta (duas vias), nessa etapa do programa, foi predominante entre os cidadãos e os órgãos envolvidos; prefeitura como articulador e Cohab como promotor do programa.

De acordo com os depoimentos coletados, em ambas as situações (moradias urbanas e rurais), o primeiro contato com o programa foi facilitado pelo agente que se encontrava na ponta do processo, e muitas vezes por informações dentro da própria comunidade. Esse primeiro movimento situa-se na posição I1 da matriz de coprodução. Este ponto em comum corresponde na matriz de análise à requisição de assistência feita pelo cidadão. Observa-se, neste caso, que há um processo preliminar de interação entre cidadão e agente, em que este (agente público) identifica as necessidades daquele (cidadão). Vejamos agora algumas diferenças entre as duas situações estudadas.

Na situação 1 (moradias urbanas, município de Palhoça), pode-se observar, na matriz de análise, que o tipo de coprodução oscila da posição I1 para a I2 e, eventualmente, para I3. Este movimento ocorre porque o cidadão, beneficiário do Programa, parte de uma requisição para a resolução de seu problema, e no decorrer do tempo interage mais frequentemente com o agente, até o momento da finalização de sua obra. A Cohab, promovendo auxílio técnico, interage com os beneficiários nos ajustes mútuos de acordo com a necessidade do beneficiário individual. Assim, o beneficiário exerce influência no atendimento às suas necessidades dentro dos limites legais e técnicos que cabem ao órgão. 
Quadro 2

Matriz de coprodução Programa Nova Casa - Palhoça

\begin{tabular}{|cccc|}
\hline Coprodução do bem público & \multicolumn{3}{c|}{ Formas possiveis de envolvimento } \\
\hline Tipologias & $\begin{array}{c}\text { Requisição de } \\
\text { assistência }\end{array}$ & $\begin{array}{c}\text { Cooperação (não) com } \\
\text { agentes }\end{array}$ & $\begin{array}{c}\text { Negociação com } \\
\text { agentes }\end{array}$ \\
Individual (I) & $(1)$ & $(2)$ & $(3)$ \\
Grupal (G) & 11 & 12 & 13 \\
Coletiva (C) & & & \\
\hline
\end{tabular}

Fontes: elaboração dos autores, com base em Withaker (1980) e Brudney e England (1983).

Na situação 2 (moradias rurais, município de Rancho Queimado), o processo também começa com a requisição do beneficiário (posição I1). Nesta situação, a prefeitura, depois de selecionadas as famílias a serem beneficiadas pelo programa, coordenou atividades entre esses beneficiários, em relação à nova moradia. Essas atividades tinham como objetivo articular a execução da obra dos beneficiários, criando uma dinâmica participativa nesse nível. Nesse caso, observa-se, na matriz de análise, a evolução do tipo de coprodução da posição I1 para a posição G2, na qual um grupo começa a interagir e a participar, na pré-execução da obra de suas casas. A prefeitura teve um relacionamento muito próximo aos beneficiários, fornecendo a expertise técnica, enquanto os beneficiários interagiam dentro de seu grupo por meio de reuniões, melhorando, desta forma, qualitativamente o resultado final das construções. Durante todo esse processo, os assuntos debatidos nessas reuniões apresentaram um cunho educativo e de envolvimento do grupo. Buscou-se formar um sentimento de união, de preocupação com o coletivo, relacionando o programa com os objetivos mais amplos de desenvolvimento do município. Tal iniciativa se alinha à construção de um espaço público para a deliberação, em que os cidadãos expõem seus problemas e os discutem em termos coletivos. Buscou-se, dessa forma, mesmo que em nível de execução, o envolvimento positivo dos beneficiários, por meio de um processo que é idêntico aos experimentos sociais propostos por Roberts (2004). Observou-se, também, que os beneficiários fortaleceram o senso de identidade comunitária e de pertencer ao local onde vivem; à medida que os agentes e os cidadãos beneficiários deliberaram sobre a construção das casas, eles desenvolveram um senso de identidade entre os membros do grupo. Esse benefício se estendeu para além do grupo, alcançando a comunidade. Neste caso, a coprodução da habitação passa a ser coletiva, por meio da coletividade que negocia com os agentes públicos. Na matriz de análise pode-se observar um movimento de maior participação e interação entre a coletividade e os agentes públicos. Os experimentos desenvolvidos no caso de Rancho Queimado ressaltam a importância do envolvimento do cidadão na implementação do programa habitacional e reforçam a importância da construção de uma consciência coletiva de valores comunitários.

A matriz de análise permite verificar que, no caso de Rancho Queimado, houve uma interação crescente entre cidadão e agentes públicos. No início do processo de coprodução, 
o cidadão requisitou, individualmente, a assistência do agente público (I1); depois, com os demais beneficiários, em grupo, cooperou com agentes públicos (G2); e, ao final do processo, houve a ação coletiva, com negociação com os agentes públicos (C3), na medida em que os assuntos discutidos nas reuniões conduzidas com os beneficiários iam além da construção da moradia e envolviam matérias pertinentes a uma coletividade. A matriz a seguir (quadro 3) permite visualizar a participação e o envolvimento do beneficiário no processo de coprodução de sua moradia para a situação em questão. Fica evidente, na matriz, que a coprodução da moradia evoluiu de um envolvimento individual para uma interação coletiva. Ainda, na fase de planejamento do processo de coprodução da moradia, o beneficiário fez a requisição de assistência (I1).

Quadro 3

Matriz de coprodução Programa Nova Casa - Rancho Queimado

\begin{tabular}{|c|c|c|c|}
\hline \multirow{2}{*}{$\begin{array}{c}\text { Coprodução do bem público } \\
\text { Tipologias }\end{array}$} & \multicolumn{3}{|c|}{ Formas possíveis de envolvimento } \\
\hline & $\begin{array}{l}\text { Requisição de } \\
\text { assistência } \\
\text { (1) }\end{array}$ & $\begin{array}{c}\text { Cooperação (não) com } \\
\text { agentes } \\
\text { (2) }\end{array}$ & $\begin{array}{c}\text { Negociação com } \\
\text { agentes } \\
\text { (3) }\end{array}$ \\
\hline Individual (I) & 11 & & \\
\hline Grupal (G) & & G2 & \\
\hline Coletiva (C) & & & C3 \\
\hline
\end{tabular}

Fontes: elaboração dos autores, com base em Withaker (1980) e Brudney e England (1983).

À medida que os beneficiários reuniam-se e, em conjunto, debatiam e esclareciam as matérias pertinentes à construção de sua moradia, estabeleceu-se uma cooperação com os agentes em nível grupal (G2). A prefeitura de Rancho Queimado, pela ação dos agentes que se encontravam na ponta do processo, teve papel fundamental na efetividade do programa, pois auxiliava os beneficiários com as questões cadastrais e documentais exigidas. Durante esse processo, houve, segundo relatos da prefeitura, até mesmo alguns recadastramentos de cidadãos, pois necessitavam de documentos básicos, como carteira de identidade e CPF. Esse relacionamento evolui para uma negociação com agentes (C3), que atuam, nos encontros com os grupos de beneficiários, introduzindo matérias de interesse comunitário (coleta de lixo, cuidados com animais, questões de saneamento etc.) e negociando aspectos pertinentes à moradia do beneficiário, já em execução. No caso em estudo, tanto o envolvimento coletivo quanto a negociação com agentes demonstram que houve participação dos envolvidos no processo de coprodução da moradia como bem público. A teorização sobre participação do cidadão e coprodução do bem público, que sustenta esse estudo, permite afirmar, para a situação de Rancho Queimado, que o programa contribuiu para o fomento da democracia naquela comunidade.

As diferenças, observadas entre a situação de Rancho Queimado e Palhoça, merecem algumas considerações. A prefeitura, em ambos os casos, atua como parceira da Cohab na ope- 
racionalização do programa. No entanto, características como tamanho do município podem influenciar em como os cidadãos abordam a administração pública. Segundo estimativas do IBGE (2009), as populações de Rancho Queimado e Palhoça eram, respectivamente, de 2.893 e 130.878 habitantes. Além disso, existem as diferenças entre o perfil rural de uma e urbano de outra. Daí poder se deduzir que a estrutura cívica de cada cidade pode variar e demandar diferentes mecanismos para a participação do cidadão. Como ressalta Morton e colaboradores (2008), estruturas cívicas bem desenvolvidas requerem múltiplas conexões entre comunidade e outras organizações, na busca de resolução dos problemas públicos. Ou seja, de um lado, o contato, a proximidade do cidadão à administração pública, mesmo não existindo organizações intermediárias entre estes, como associações de bairro ou outras entidades representativas, varia de caso para caso. Por outro lado, a prefeitura de Rancho Queimado, por possuir uma demanda menor que Palhoça, possuía mais flexibilidade em negociar com os subsidiários.

\section{Considerações finais}

O estudo desenvolvido neste artigo evidencia que a participação do cidadão na implementação de políticas públicas, coproduzindo o bem público, é viável e produz benefícios para a sociedade, embora ainda apresente desafios a serem superados. Os resultados deste estudo devem ser complementados por outras pesquisas para que se possa ampliar o grau de generalização que ainda exige a construção teórica sobre a coprodução do bem público.

Também se faz necessário que a matriz de análise da coprodução, proposta neste artigo, agregue maior número de variáveis, com base em teorias sobre participação política, sobre coprodução e produção do bem público com eficiência, eficácia e responsividade. Neste sentido, estudos podem vir a estabelecer uma correlação entre a participação no processo de coprodução e a qualidade dos serviços produzidos. Também são necessários estudos para verificar a correlação entre a participação do cidadão no processo de coprodução e o fomento da democracia. Esta é uma área em que pode vir a ser estabelecida uma ponte entre os estudos sobre rede de coprodução do bem público e capital social da comunidade. Há a necessidade, também, de se compreender o processo de participação do cidadão em fóruns e seminários que visam ao desenvolvimento de programas e aos resultados a que leva essa participação. É importante ressaltar que as recomendações feitas até aqui não devem inibir outras possibilidades de pesquisa e estudo sobre a coprodução do bem público.

Embora haja necessidade de se promover estudos sobre o tema discutido no artigo, o propósito traçado para este estudo permite iluminar a importância da participação do cidadão no processo de coprodução. Essa participação, como predicado inerente ao ser humano, alcança um resultado que vai além da eficiência e da eficácia na coprodução do bem público. Ela alcança a dimensão política do ser humano, fator essencial e necessário para o exercício da democracia. Essa assertiva leva à conclusão de que os processos de coprodução do bem público que privilegiam a participação efetiva do cidadão emprestam importante contribuição à democracia. 


\section{Referências}

ARENDT, Hannah. A condição humana. 8. ed. Rio de Janeiro: Forense Universitária, 1997.

BISHOP, Patrick; DAVIS, Glynn. Mapping public participation. Australian Journal of Public Administration, v. 61, n. 1, p. 14-29, 2002.

BRUDNEY, J.L.; ENGLAND, R.E. Toward a definition of the coproduction concept. Public Administration Review, v. 43, n. 1, p. 59-65, 1983.

BUARQUE DE HOLANDA, Sérgio. Raízes do Brasil. São Paulo: Cia. das Letras, 1995.

COHEN, M.D.; MARCH, J.G. Leadership and ambiguity: the American college president. Boston: Harvard Business School Press, 1974.

COOPER, T.L.; KATHI, P.C. Neighborhood councils and city agencies: a model of collaborative coproduction. National Civic Review, p. 43-53, Spring 2005.

DAHL, Robert A. A preface to democratic theory. Chicago: University of Chicago Press, 1956.

DENHARDT, Robert B.; DENHARDT, Jane Vinzant. The new public service: serving, not steering. Armonk, NY: M.E. Sharpe, 2003.

FARAH, Maria Ferreira Santos. Parcerias, novos arranjos institucionais e políticas públicas no nível local de governo. Revista de Administração Pública, v. 35, n. 1, p. 119-144, jan./fev. 2001.

FARREL, Catherine M. Citizen participation in governance. Public Money \& Management, Jan./Mar. 2000.

HARBERS, Imke. Democratic deepening in third wave democracies: experiments with participation in Mexico City. Political Studies, v. 55, p. 38-58, 2007.

MARSCHALL, Melissa J. Citizen participation and the neighborhood context: a new look at the coproduction of local public goods. Political Research Quarterly, v. 57, n. 2, p. 231-244, Jun. 2004.

MELUCCI, Alberto; AVRITZER, Leonardo. Complexity, cultural pluralism and democracy collective action in the public space. Social Science Information, v. 39, n. 4, p. 507-527, 2000.

MERRIAM, Sharam B. The design of qualitative research. In: MERRIAM, Sharam B. Qualitative research and case study applications in education. San Francisco: Jossey-Bass, 1988. p. 1-34.

MORTON, L.W. et al. Solving problems of Iowa food deserts: food insecurity and perceptions of civic structure. Rural Sociology, v. 70, n. 1, p. 94-112, 2005.

MORTON, L.W.; CHEN, Yu-Che; MORSE, Ricardo S. Small town civic structure and interlocal collaboration for public services. City \& Community, v. 7, n. 1, Mar. 2008.

ORTON, J.D.; WEICK, K.E. Loosely coupled systems: a reconceptualization. The Academy of Management Review, v. 15, n. 2, p. 203-223, 1990. 
ORUM, A.M.; GRAMLICH, J. Civic capital and the construction (and reconstruction) of cities. Colloquy, p. 45-54, 1999.

RANSON, S.; STEWART, J. Citizenship and government: the challenge for management in the public domain. Political Studies, v. 37, p. 5-24, 1989.

ROBERTS, Nancy. Public deliberation in an age of direct citizen participation. American Review of Public Administration, v. 34, n. 4, p. 315-353, Dec. 2004.

ROWE, Gene; FREWER, Lynn J. A typology of public engagement mechanisms. Science, Technology, and Human Values, v. 30, n. 2, p. 251-290, 2005.

SUNDEEN, Richard. Coproduction and communities: implication for local administrators. Administration and Society, v. 16, n. 4, Feb. 1985.

STEWART, Kennedy. Write the rules and win: understanding citizen participation game dynamics. Public Administration Review, Nov./Dec. 2007.

VIEIRA, Liszt. Cidadania e globalização. Rio de Janeiro: Record, 1997.

WALTERS, Lawrence C.; AYDELOTTE, James; MILLER, Jessica. Putting more public in policy analysis. Public Administration Review, v. 60, n. 4, p. 349-359, 2000.

WARREN, M.E. Democracy and association. Princenton, NJ: Princeton University Press, 2001.

WHITAKER, Gordon P. Coproduction: citizen participation in service delivery. Public Administration Review, v. 40, p. 240-246, May/Jun. 1980.

YIN, Robert K. Estudo de caso: planejamento e métodos. 3. ed. São Paulo: Bookman, 2005.

Vitor Hugo Klein Jr. é mestre em gestão estratégica das organizações pela Universidade do Estado de Santa Catarina (Esag/Udesc). E-mail: vklein@hsu-hh.de.

José Francisco Salm é professor visitante do Núcleo de Pós-Graduação em Administração da Universidade Federal da Bahia (NPGA/UFBA). E-mail: jfsalm@uol.com.br.

Francisco G. Heidemann é professor aposentado da Universidade Federal de Santa Catarina (UFSC) e da Udesc. E-mail: heidex0@gmail.com.

Maria Ester Menegasso é professora da Udesc. E-mail: mester@udesc.br. 